Estudios sobre el Mensaje Periodístico

ISSN-e: 1988-2696

http://dx.doi.org/10.5209/esmp.69698

\title{
Diversidad en clave de insularidad: el mapa de la radiotelevisión local en Canarias
}

\author{
Azahara Cañedo
}

Recibido: 22 de mayo de 2020 / Aceptado: 7 de julio de 2020

Resumen. Este artículo presenta un mapa estructural de los agentes que operan, a través del espectro radioeléctrico, en el sector de la radio y la televisión local en Canarias. El objetivo es caracterizar el sistema comunicativo local en el territorio, tomando como principal línea de reflexión científica la investigación sobre el concepto de diversidad aplicada al campo de las industrias audiovisuales (McQuail, 1998; Napoli, 1999; Albornoz y García Leiva, 2017a y 2017b). A partir del análisis de los agentes concesionarios de licencias de radiodifusión y de las señales emitidas a través de ellas, la investigación revela que el mapa se configura en torno a una idea de diversidad entendida como insularidad, en concordancia con el modelo de organización territorial de Canarias.

Palabras clave: Islas Canarias; diversidad audiovisual; radiodifusión local; espectro radioeléctrico; comunicación de proximidad

\section{[en] Diversity in terms of Insularity: The Map of Local Broadcasting in the Canary Islands}

\begin{abstract}
This article presents a structural map of the agents operating in the local radio and television sector in the Canary Islands throughout the spectrum. The objective is to characterize the local communication system in the territory, taking as the main line of scientific reflection the research on the concept of diversity applied to the field of audiovisual industries (McQuail, 1998; Napoli, 1999; Albornoz and García Leiva, 2017a and 2017b). Based on the analysis of the agents that are granted broadcasting licenses and the signals emitted through them, the research reveals that the map is configured around an idea of diversity understood as insularity, in accordance with the territory.
\end{abstract}

Keywords: Canary Islands, Audiovisual Diversity, Local Broadcasting, Spectrum, Communication of Proximity

Sumario: 1. Introducción 2. Metodología 3. Discusión de resultados 3.1. El mapa radiofónico local 3.1.2. Las radios privadas locales 3.2. El mapa televisivo local 4. Conclusiones 5. Referencias bibliográficas 6 . Anexos

Cómo citar: Cañedo, A. (2020). Diversidad en clave de insularidad: el mapa de la radiotelevisión local en Canarias. Estudios sobre el Mensaje Periodistico 26 (4), 1325-1340. http://dx.doi.org/10.5209/esmp.69698

\section{Introducción}

La diversidad se ha convertido en protagonista de las políticas de comunicación desde que la Organización de las Naciones Unidades para la Educación, la Ciencia y la Cultura aprobara la Convención sobre la protección y la promoción de la diversidad de las expresiones culturales (UNESCO, 2005). Este instrumento jurídico, que continua el camino iniciado por la Declaración universal de la UNESCO sobre Diversidad Cultural (UNESCO, 2001), es clave para el impulso del estudio de esta problemática en el ámbito de las industrias culturales. La Convención es el primer tratado internacional que pone en valor su doble dimensión económica y cultural (Barreiro en Albornoz y García Leiva, 2017b: 60-61). En este sentido, presta especial atención a la creación y consolidación de industrias culturales en los mercados locales y regionales, con "referencias explícitas [...] que ponen de manifiesto que no es posible pensar la diversidad de las expresiones culturales sin conside- rar su dimensión de proximidad" (García Leiva en Nerekan Umaran et al., 2015: 45). Una idea que, en el seno de la UNESCO, se ve reforzada con la apuesta por lo local evidenciada también en la Declaración de Hangzhou (UNESCO, 2013).

Analizar la diversidad de las industrias audiovisuales locales, en el actual contexto de saturación de los mercados, pasa por prestar atención a la estructura mediática. Es lo que Denis McQuail (1998: 234) denomina diversidad externa y que implica poner en contexto a todos los agentes que operan estructuralmente en un mismo espacio geográfico-temporal. A este concepto, McQuail suma el de diversidad geográfica que presta atención al origen de los contenidos. En este sentido, se preocupa por conocer si las localidades y regiones cuentan con medios de comunicación propios; si los sistemas mediáticos locales ofrecen una posibilidad de elección real entre canales, si su oferta es suficiente para suplir a los medios nacionales; y si estos últimos prestan la atención debida a las regiones (McQuail, 1998: 227-231).

\footnotetext{
Universidad de Castilla-La Mancha (España)

E-mail: azahara.canedo@uclm.es
} 
$\mathrm{Al}$ respecto, considera que el modelo estructural del sistema mediático es definitorio y alerta de que el modelo comercial tiende a reducir la oferta local: se corre el riesgo de que los canales locales pertenezcan a grupos de comunicación que operan en la totalidad del ámbito estatal ofreciendo contenidos similares en espacios geográficos diferenciados. Para evitar esto, señala McQuail, los medios deberán pertenecer a propietarios locales e incluir canales independientes que compitan entre sí.

A partir del trabajo previo de otros autores en torno a la problemática de la diversidad (Napoli, 1999; Stirling, 2008), el grupo de investigación Diversidad Audiovisual $^{2}$ ha desarrollado una propuesta propia de medición de la diversidad en la industria audiovisual que ya ha sido aplicado en estudios relativos al ámbito regional (Cañedo, 2018 y 2019). En línea con lo señalado por McQuail, esta propuesta mantiene que para evaluar la diversidad en un sistema audiovisual ha de tenerse en cuenta, entre otros factores, que "la capacidad de producción, distribución y exhibición/emisión de contenidos audiovisuales no esté concentrada en un número reducido de agentes y que estos agentes sean de diferentes tipos de titularidad, tamaño y origen geográfico" (Albornoz y García Leiva, 2017b: 32).

Así, a partir de estos trabajos previos, el presente artículo de investigación tiene como objeto mapear el sector de radiotelevisión local de la Comunidad Autónoma de Canarias. En esta región, caracterizada en su Estatuto de Autonomía por su lejanía, insularidad y condición ultraperiférica, la cuestión de la diversidad se torna especialmente determinante. La importancia de lo local se evidencia en el modelo de organización de este archipiélago compuesto por siete islas con administración propia ${ }^{3}$, que no solo es la única comunidad autónoma española organizada en torno a la figura administrativa del cabildo insular sino también la única con capitalidad compartida. Las particularidades de la región "hacen del territorio canario un espacio donde lo que realmente domina es la diversidad, donde todo cambia no sólo de una isla a otra, sino en el interior de cada una de ellas" (Morales Mato, 2001: 158).

$\mathrm{Su}$ carácter insular ha sido calificado como "una de las peculiaridades más negativas de Canarias [ya que] puede llegar a producir graves desequilibrios intrarregionales" (Morales Mato, 2001: 173). Esto se evidencia si se atiende a indicadores demográficos y económicos. Por ejemplo, la distribución especial de la población (Ramos Pérez, 2005: 254), que se concentra mayoritariamente en las dos islas capitales: Tenerife $(42,6 \%)$ y Gran Canaria $(39,5 \%)^{4}$. El resto, se reparte desequilibradamente entre las demás islas, siendo ma- yoritaria la concentración de población en las otras dos islas de la provincia de Las Palmas de Gran Canaria, Lanzarote $(7,1 \%)$ y Fuerteventura $(5,4 \%)$. Por su parte, en las islas de La Palma, La Gomera y El Hierro, los datos de población no superan en ningún caso el umbral del $4 \%$ (3,9\%, $1 \%$ y $0,5 \%$, respectivamente). Los indicadores económicos ${ }^{5}$ de PIB y tasa de empleo reafirman estos desequilibrios territoriales: Tenerife y Gran Canaria concentran el mayor volumen de PIB (44\% y $37,9 \%$ ) y empleo ( $43,3 \%$ y 38,35$)$, seguidas de Lanzarote (7,8\% para ambos indicadores) y Fuerteventura $(5,6 \%$ y $5,8 \%)$. La Palma no supera el umbral del $4 \%$ en ninguno de los indicadores y El Hierro y la Gomera ni siquiera alcanzan el del $1 \%$.

Lo insular, entendido como espacio territorial superior al local pero inferior al regional, motiva la elección de Canarias como objeto de estudio. A partir de los conceptos de diversidad externa y geográfica, el artículo pretende caracterizar el espacio de radiotelevisión local de Canarias atendiendo a su particularidad territorial. Así, se plantea la pregunta general ¿cómo se caracteriza, en términos de diversidad, el espacio de radiotelevisión local en Canarias? Para responderla, se atiende a la naturaleza de las empresas (titularidad y origen geográfico) que emiten a través del espectro radioeléctrico en el sector de la radio y la televisión local en Canarias y a la oferta programática de estos operadores.

\section{Metodología}

Al realizar una investigación sobre espacios de radiotelevisión locales es determinante entender que no existe un modelo único ya que estos espacios están fuertemente condicionados por los contextos en los que se desarrollan. Por ello, la primera decisión metodológica es la elección del estudio de caso como método científico. Si bien, a pesar de que este tipo de estudios son habitualmente desafiados por la investigación teórica ante la tendencia errónea de considerarlos demasiado específicos, es importante destacar su valor para generalizar proposiciones teóricas (Yin, 2003). La elección del caso canario responde a las particularidades y condiciones contextuales del territorio seleccionado, ya explicadas, que resultan de especial pertinencia para el fenómeno estudiado: la diversidad externa y geográfica de un espacio comunicativo local. Por ello, el estudio de caso estudiado en este artículo ha de servir para representar un aporte significativo a la construcción teórica sobre el tema.

La metodología aplicada para responder a la pregunta de investigación planteada incluye dos técnicas científicas. La principal es el análisis documental. Se

\footnotetext{
El grupo de investigación Diversidad Audiovisual, del que la autora del artículo forma parte, tiene su sede en el Departamento de Comunicación de la Universidad Carlos III de Madrid y centra sus investigaciones en la problemática de la diversidad en las industrias culturales, en general, y en el sector audiovisual digital, en particular. Más información en: http://diversidadaudiovisual.org

Estas islas son: El Hierro, La Palma, La Gomera, Tenerife, Gran Canaria, Lanzarote y Fuerteventura. Las cuatro primeras forman parte de la provincia de Santa Cruz de Tenerife, cuya capitalidad se ubica en la isla de Tenerife; mientras que las tres últimas constituyen la provincia de Las Palmas, con capital en la isla de Gran Canaria.

Datos para el año 2019. Fuente: Padrón Municipal de Habitantes.

Datos para el año 2018. Fuente: Instituto Canario de Estadística (ISTAC) a partir de datos del Instituto Nacional de Estadística (INE).
} 
ha realizado una búsqueda y sistematización de datos sobre nuestro objeto de estudio a través de distintas fuentes documentales: bases de datos sectoriales y estadísticas, memorias anuales sectoriales, y documentación oficial de los medios de comunicación presentes en Canarias. Además; se han consultado y analizado otras fuentes documentales que permiten contextualizar los datos: legislación y normativa jurídica; documentos oficiales y no oficiales de la Administración autonómica y estatal, de la industria y de la sociedad civil; hemeroteca de prensa; publicaciones académicas y webs no oficiales sobre información del sector audiovisual canario.

Al respecto del uso y tratamiento de la información documental referida y de cara a evitar posibles errores de decodificación de la información, se han tomado las siguientes decisiones metodológicas:

- La caracterización de las empresas audiovisuales y sus vinculaciones se realiza prioritariamente a partir de la información registral contenida en la base de datos SABI. La información registral obtenida ha sido actualizada por última vez el 31 de enero de 2020.

- Se entiende por grupo de comunicación a toda empresa de comunicación que posee ramas de actividad en más de un sector de la comunicación (radio, televisión y prensa).

- Se consideran empresas canarias y/o regionales a aquellas con domicilio social en alguna de las islas que componen el archipiélago canario.

Como metodología secundaria, se ha entrado en contacto, de manera puntual, vía telefónica o correo electrónico, con los responsables de los medios/empresas referidos en el presente artículo. El objetivo ha sido realizar entrevistas específicas a las fuentes primarias con la finalidad de resolver dudas o lagunas respecto a la naturaleza de su actividad, especialmente respecto a los contenidos emitidos.

El conjunto de los datos obtenidos sobre las concesiones administrativas de licencias de radio y televisión local en Canarias, la unidad básica de análisis de esta investigación, se ha analizado en términos de diversidad tomando en cuenta los factores de variedad y balance (Stirling, 1998 y 2007). La variedad guarda relación con el número de diferentes tipos o categorías mientras que el balance considera los diferentes grados en que los tipos o categorías definidos se encuentran representados en el sistema; los cuales pueden medirse, por ejemplo, en porcentajes (Albornoz en Albornoz y García Leiva, 2017b: 204). Estos factores se han aplicado sobre un modelo de medición de la diversidad audiovisual organizada y clasificada a través de los siguientes parámetros:

- Tipo de licencia asignada y ámbito de servicio.
- Naturaleza de la sociedad concesionaria de la licencia en función de su titularidad (privada o pública), su domicilio social y su pertenencia a grupos de comunicación.

- Contenido emitido a través de la frecuencia asignada en función de su origen y su tipología.

Para facilitar la decodificación de los resultados, la discusión de los mismos se ha ordenado por sectores: de un lado, el sector radiofónico; de otro lado, el sector televisivo. Dentro de cada uno, estos se muestran organizados en torno a las divisiones establecidas en los respectivos Planes Técnicos de ordenación del espectro radioeléctrico.

\section{Discusión de resultados}

\subsection{El mapa radiofónico local}

El mapa radiofónico de la Frecuencia Modulada $(\mathrm{FM})^{6}$ en el conjunto del territorio estatal está constituido por emisiones gestionadas por las administraciones públicas -a nivel estatal, autonómico y local (emisoras municipales)- y por personas físicas o jurídicas (emisoras privadas). Las emisoras municipales, con una larga trayectoria en el conjunto del estado $\mathrm{y}$ una presencia desigual por territorios (Chaparro, 1998), están gestionadas por las corporaciones locales previa petición de concesión de licencia local a la autoridad correspondiente. Por su parte, en el caso de las emisoras privadas, las licencias también son de ámbito local y su asignación corresponde a las comunidades autónomas tras concurso público.

La configuración del mapa de radio local a nivel estatal sigue unos patrones comunes: concesiones a adjudicatarios afines a los gobiernos, control político y dominio de las cadenas de ámbito estatal (Arboledas, 2009: 909). Esto ha dado como resultado mapas de radio local dominados por pocos concesionarios privados de ámbito estatal, en la mayoría de los casos grupos de prensa que expanden su negocio e influencia, siendo insignificante la presencia de empresas locales independientes (Arboledas, 2009; Bonet y Arboledas, 2011; Badillo y Pérez Alaejos en Gallego y García Leiva, 2012; Arboledas y Bonet, 2013; Fernández-Sande y Gallego, 2019). Lo apuntado indica una escasa diversidad externa y confirma las preocupaciones apuntadas por McQuail sobre la diversidad geográfica en los espacios mediáticos locales. En el caso canario, como se detalla en los próximos epígrafes, se repite esta dinámica.

\subsubsection{Las radios municipales canarias}

El mapa actual de radio pública local en Canarias comienza a configurarse en 1993, un poco más tarde que en el resto del territorio estatal donde su definición se

En España aún no se ha producido el apagón de la radio analógica. Como señala David Fernández-Quijada (en Bonet, 2016: 187), esto se debe a que "no existe utilización alternativa del espectro de FM una vez liberado, lo que hace limitado su valor económico e impensable para el legislador una transición forzosa como la que se realizó con la televisión digital terrestre". 
produce a partir de la llegada de la democracia (Chaparro, 1998). Desde entonces, hasta 2008, momento en el que se otorga la concesión más reciente, se identifica la existencia de 31 concesiones para emisoras municipales en FM (Anexo I). De este total, 21 de ellas se mantienen activas $(67,85 \%)$, más de la mitad operativas desde la década de 1990, lo que define un panorama de radio municipal estable en el tiempo. Respecto a las diez emisoras inactivas, solo en cinco de ellas no consta que haya existido emisión en algún período de tiempo desde la asignación de la concesión. Estos datos permiten identificar un interés real, por parte de las corporaciones locales, en el mantenimiento de sus radios municipales. Si bien, la apuesta por ellas aún es minoritaria ya que apenas el 35\% de los municipios canarios posee licencia.

Si se atiende a la distribución geográfica, la mayor concentración de estas concesiones con emisoras activas se localiza en la provincia de Las Palmas (57\%). En concreto, en municipios de Gran Canaria donde se localizan 11 de las 12 concesiones operativas en la provincia, mientras que la doceava concesión mencionada se localiza en Lanzarote. Esta lógica se repite en la provincia de Santa Cruz de Tenerife, donde las emisiones se concentran en la isla capital, Tenerife (33\%), que cuenta con ocho de las nueve radios municipales. La novena se ubica en La Gomera. Así, a pesar de la variedad en el número de señales, se evidencia un desbalance de presencia entre islas que pone de manifiesto que la apuesta por las radios municipales se concentra en las islas capitales a la vez que evidencia el desinterés por parte de los municipios del resto de islas.

Respecto al contenido, todas las emisoras municipales programan contenidos de proximidad, es decir, que ponen de manifiesto que "entre la emisora y sus receptores existe un escenario de experiencias compartidas" (Moragas et al., 1999: 19). La atención preferente es a la información local, cumpliendo así con lógicas de servicio público, pero también dan ca- bida a informaciones insulares y regionales. En este sentido, en términos de diversidad, existe una alta variedad en la oferta, no solo en cuanto al origen de los contenidos sino también a su propia naturaleza temática y profesionalización. Se destaca que todas tienen en su propuesta fundamental la participación ciudadana ya que se identifican múltiples colaboraciones con asociaciones vecinales y empresariales locales e incluso con centros educativos.

\subsubsection{Las radios privadas locales}

Las 167 licencias de FM local asignadas -de las 200 planificadas- para la gestión indirecta de medios radiofónicos por parte de personas físicas o jurídicas recaen sobre 35 sociedades concesionarias de diversa naturaleza. Respecto a su titularidad y origen geográfico, se identifican empresas dependientes de grandes grupos de comunicación estatal; empresas regionales vinculadas con grupos de comunicación de ámbito regional; y empresas independientes, tanto regionales como de otras provincias (Anexo II). Si bien, estas últimas representan apenas el 17,4\% de las concesiones asignadas.

Los siete grupos de ámbito estatal con concesión de licencia aglutinan el 47,3\% de las concesiones y son los ya habituales en el panorama radiofónico estatal (Arboledas y Bonet, 2013: 216; SGAE, 2019): PRISA, COPE, Atresmedia, Radio Blanca, y Radio María; a los que se suman Prensa Ibérica Media y Vocento. El que posee mayor número de concesiones es Radio Blanca (29), siendo el único con concesión para emitir en las siete islas principales. Si bien, su reparto en volumen es desequilibrado ya que se concentra mayoritariamente en las islas capitales, donde aglutina el $62 \%$ de la emisión asignada. A través de sus licencias emite señales propias: Kiss $F M$, en todas las islas, y Hit FM en Tenerife, Gran Canaria y Fuerteventura.

Figura 1. Canarias: licencias de radiodifusión FM concesionadas a grupos de comunicación de ámbito estatal. Elaboración propia a partir del Registro Público de Concesiones y de información corporativa facilitada por cada medio.

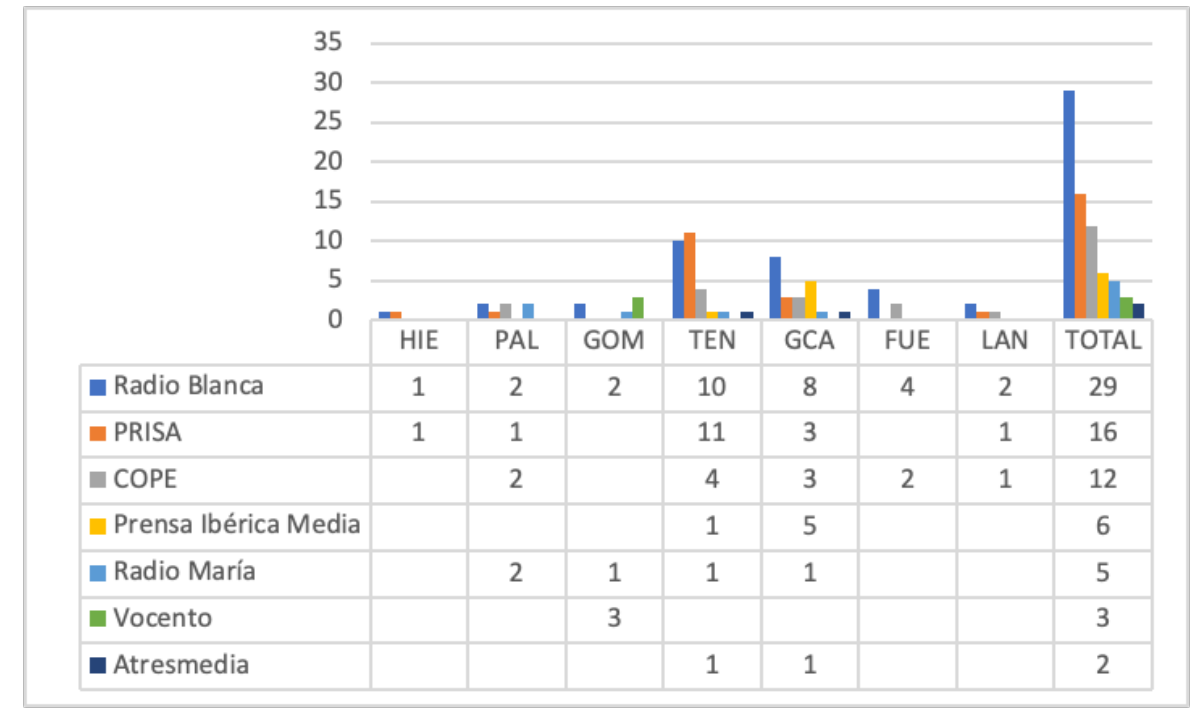


El segundo grupo de comunicación de ámbito estatal por número de concesiones es PRISA, concesionario a través de dos empresas: Sociedad Española de Radiodifusión (8) y Radio Club de Canarias (8). Ambas emiten señales propias del grupo en las cinco islas en las que tienen licencias, con mayor presencia en las islas capitales (14), especialmente en Tenerife (68,75\%). Por su parte, el grupo COPE posee 12 licencias a través de las que emite señales propias $(C O P E$ y Cadena 100) a través de dos sociedades: FM Radio Canarias S.L., con concesión en Fuerteventura, y Radio Popular S.A. Cadena de Ondas Popular, con 11 concesiones en las cinco islas con mayor población. Como en los casos anteriores, la mayor concentración se detecta en las islas capitales $(58,3 \%)$.

Grupo Prensa Ibérica Media, posee seis licencias en el territorio, gestionadas a través de dos empresas: Editorial Prensa Canaria S.L., con cinco concesiones en Gran Canaria; y Radio 21 Tenerife S.A.L., con una en Tenerife. Este grupo, por tanto, solo tiene concesiones en las islas capitales y es el único en el que la mayor parte de ellas se ubican en Gran Canaria $(83,3 \%)$. Por su parte, Atresmedia, a través de Uniprex, repite esta dinámica de presencia única con licencia en las islas capitales. En este caso, con una concesión en cada una de ellas, por las que emite su señal Onda Cero.

Otra empresa de ámbito estatal, RK20 S.L., vinculada a la Asociación Radio María tiene cinco concesiones en las islas de Tenerife, La Palma y la Gomera. En las tres que consta emisión, emite su señal propia. Por último, Vocento posee, a través de Radio Publi S.L., tres concesiones en La Palma por las que emite señales del grupo COPE, tras el acuerdo de asociación firmado entre ambos grupos a finales de $2012^{7}$. Vocento es, por tanto, el único grupo de comunicación de ámbito estatal que no posee concesiones en las islas capitales y que no emite señales propias, si bien su franja de emisión se ve configurada por la parrilla de otro grupo estatal.

Figura 2. Canarias: licencias de radiodifusión FM concesionadas a grupos de comunicación canarios. Elaboración propia a partir del Registro Público de Concesiones y de información corporativa facilitada por cada medio.

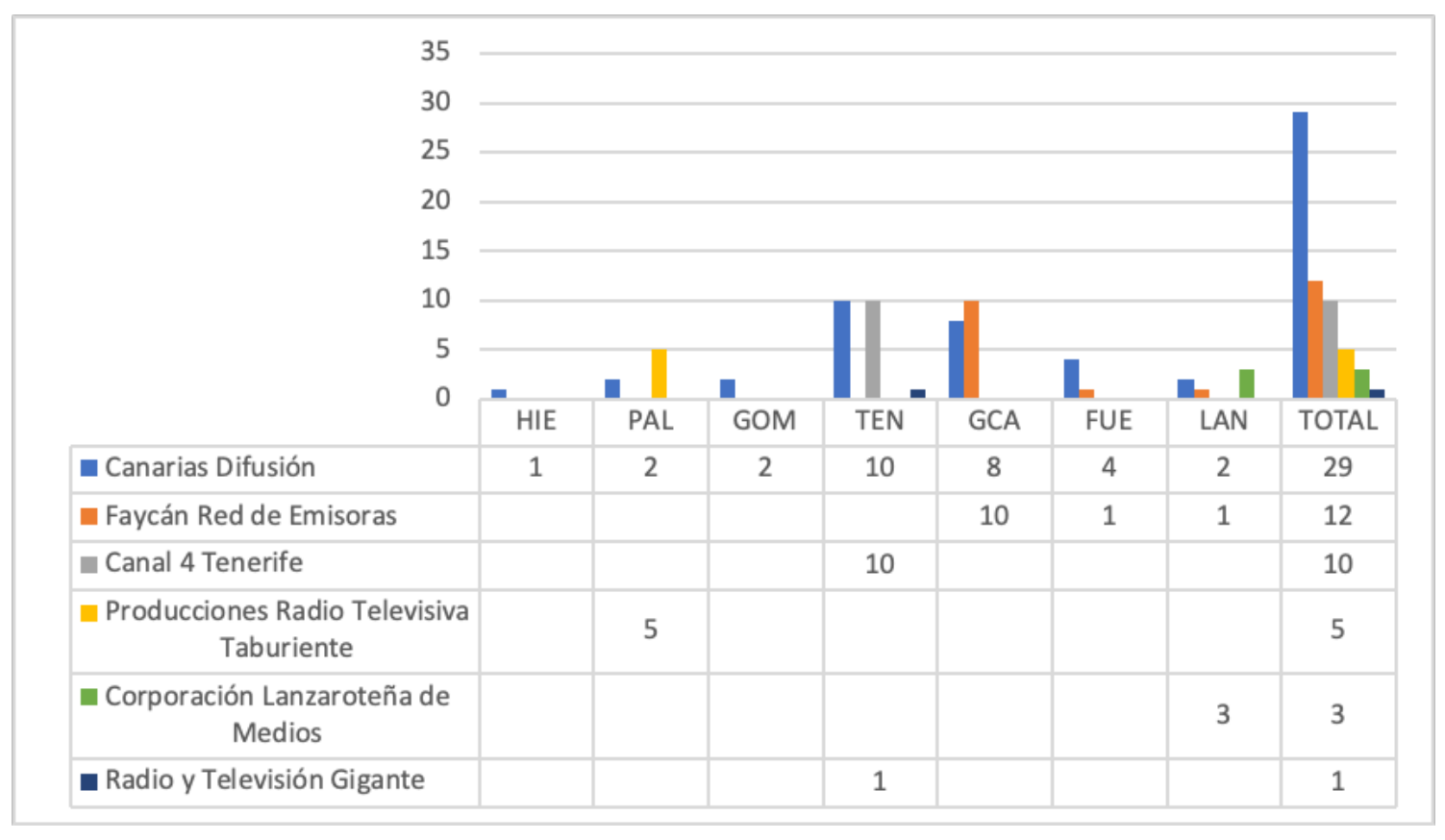

Si se atiende al origen geográfico de las concesionarias no dependientes de grupos de comunicación de ámbito estatal, 23 de las 25 adjudicatarias tienen su sede social en Canarias. Si bien, la mayoría de estas empresas se concentran en las islas capitales $(39,1 \%$ en Tenerife y $34,8 \%$ en Gran Canaria), mientras que en Lanzarote y Fuerteventura se ubican el 17,4\% y el $8,7 \%$, respectivamente. De nuevo, como ya ocurriera con el mapa de radio municipal, se destaca la ausencia de empresas concesionarias en algunas de las islas. En el caso de la FM privada, en las islas de La Palma, La Gomera y El Hierro.

Entre las empresas canarias, se identifica la presencia mayoritaria (por número de concesiones) de dos grupos de comunicación regionales, ambos con sede en Gran Canaria y más de una decena de licencias cada uno, si bien solo uno de ellos está presente en las siete islas principales. Se trata de Canarias Difusión S.L., que concentra 29 concesiones a través de las que emite su señal propia, 7 punto 7 Radio $^{8}$. Por

En 2012, Vocento y COPE firmaron un acuerdo estratégico por el que se asociaron las emisoras de ambos grupos para emitir una misma programación en cadena. Más información en: https://www.vocento.com/vocento-y-cadena-cope-alcanzan-un-acuerdo-para-reforzar-su-estrategia-editorial-y-de-negocio/

8 Aunque no consta en la información oficial de 7 punto 7 Radio, se ha confirmado que a través de dos frecuencias asignadas a Canarias Difusión en la isla de Fuerteventura se emite la señal de Radio Sintonía. 
su parte, Faycan Red de Emisoras, posee 12 concesiones en las islas de la provincia de Las Palmas, a través de las que emite su señal Radio Faycán.

La siguiente sociedad por número de concesiones es la empresa Transformaciones y Servicios S.L., que participa del accionariado de Tele Canal 4 Tenerife S.A.U. y Producciones Radio Televisiva Taburiente S.L. A través de ambas sociedades tiene concedidas un total de 15 licencias en las islas de Tenerife (10) y La Palma (5) por lo que, al igual que Faycan, concentra su actividad en una de las provincias. Aunque a través de un pequeño porcentaje de sus licencias emite Canal 4, de contenido local, esta empresa se aleja de la lógica de programar contenidos locales de los dos casos anteriores ya que a través del $86,7 \%$ de sus concesiones emite la señal de EsRadio (Libertad Digital).

Por su parte, la empresa tinerfeña Radio CIT Tenerife S.L., que posee cinco concesiones en la isla de Tenerife, también cede su espacio, en las dos licencias en las que consta emisión en activo, a contenidos de ámbito estatal, en este caso, a Capital Radio. Otras dos empresas tinerfeñas, Multipropiedad de Tenerife S.A. y Archipiélago On Air S.L., cada una con una concesión en Tenerife y otra en la Gomera emiten contenidos estatales en cadena. Así, la primera emite señales de PRISA; mientras que la segunda emite $E u$ ropa FM. Las otras cinco licencias concedidas en la isla de Tenerife se reparten entre cuatro empresas de la isla (Ideas Milenium S.L., Radio Atlántida Santa Úrsula S.L., Radio Gigante S.L., y Cadena Hit Radio Canarias S.A.U.) y una persona jurídica con domicilio en otra región (Gabriel Cerro Moreno). Esta última licencia emite la señal generalista de ámbito estatal Rock FM (COPE), mientras que, en el caso de las empresas locales, todas ellas emiten señales propias de tipo local.
En el caso de las empresas con sede social en Gran Canaria, la empresa local Radio ECCA Fundación Canaria, emite su propia señal, de tipo educativo, $R a$ dio ECCA, para islas ubicadas en las dos provincias: La Palma (2), Gran Canaria (1) y Fuerteventura (1). También emiten sus propias señales en Gran Canaria las empresas locales Radio Tamarán FM 1995 S.L. y Radio Región S.A. Sin embargo, el resto de las empresas con licencia de emisión para la isla emiten contenidos externos de ámbito estatal. Es el caso de Radio Las Palmas S.A., que emite las señales de Inolvidable FM y Es Radio; de Radio Atlántico S.L.U., que emite señal de COPE; y de Agrupación Radiofónica SA, con sede social en La Coruña, y que emite una señal de PRISA.

En exclusividad en la isla de Lanzarote poseen concesiones las empresas Editorial Lancelot, Compañía Canaria de Emisiones S.L., Comunicaciones Los Puentes S.L. y Sonido e Imagen de Canarias. La primera de ellas, perteneciente al grupo insultar Corporación Lanzaroteña de Medios, posee cuatro licencias, a través de las que emite su propia señal de radio (3) y la señal de ámbito estatal Radio Marca (1). Por su parte, cada una de las otras tres empresas posee una licencia a través de la que emiten señales de grupos de ámbito estatal: Onda Cero emite a través de la licencia de Compañía Canaria de Emisiones S.L.; COPE a través de la de Comunicaciones Los Puentes S.L.; y $S E R$ a través de la de Sonido e Imagen de Canarias. Finalmente, con concesiones únicas en Fuerteventura se localizan dos empresas: Fuerteventura Media S.L., con tres licencias a través de las que emite Radio Sintonía; y Radiodifusión Fuerteventura S.A., con una licencia a través de la que emitía la señal local Onda Fuerteventura9.

Figura 3. Canarias: contenidos en emisión de radiodifusión FM a través de emisiones con concesión de licencia (por empresa responsable de la programación). Elaboración propia a partir del Registro Público de Concesiones y de información corporativa de cada medio.

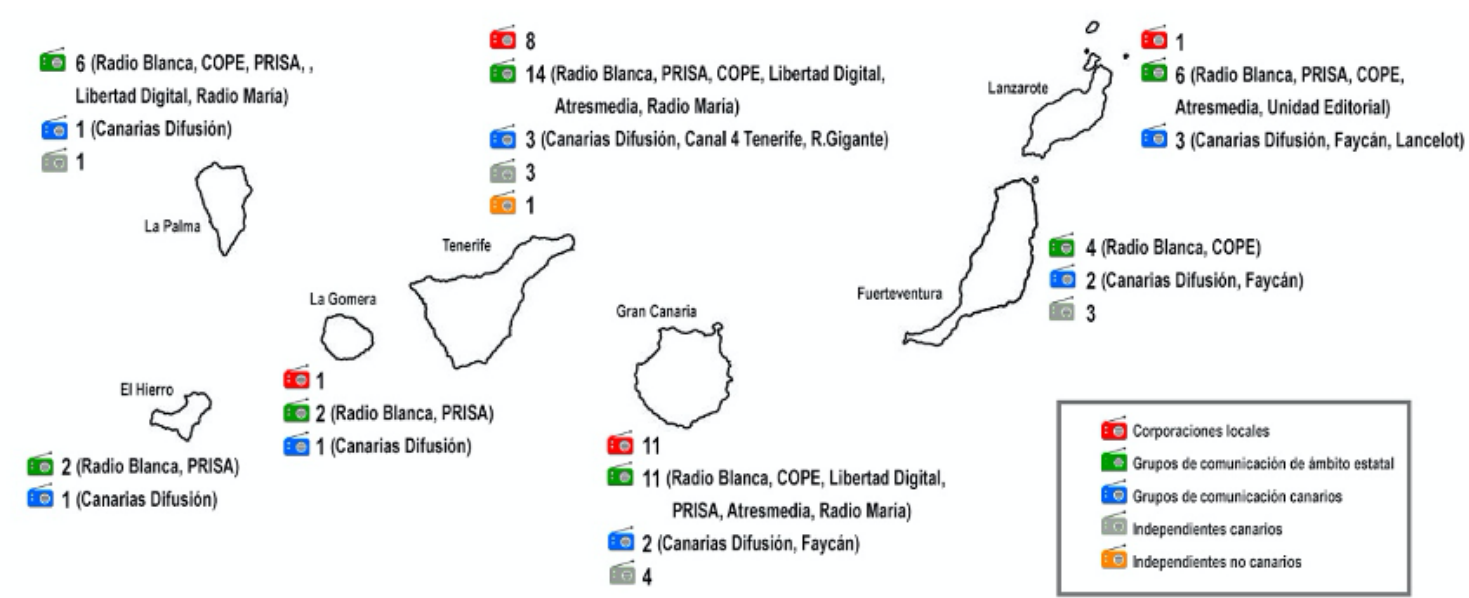

No se ha podido certificar el grado de emisión vigente. 
Si se atiende a la diversidad de los contenidos emitidos a través de estas concesiones se identifica contenido en 157 de las licenciadas asignadas (94\%) y se detecta que en el mapa canario también se repiten las lógicas habituales del resto del territorio estatal en el que conviven emisoras que operan independientemente, emisoras asociadas, emisoras afiliadas y emisoras propiedad de grandes grupos de comunicación y de sus sociedades filiales (Badillo y Pérez Alaejos en Gallego y García Leiva, 2012: 7677). La alta presencia en las concesiones de FM de los contenidos editados por grupos de ámbito estatal confirma, así mismo, que Canarias sigue las tendencias de configuración del mapa radiofónico del resto del Estado (Pedrero y Badillo en Badillo et al. 2009; Martínez de la Casa en Gallego y García Leiva, 2012; Gabilondo en Chaparro, 2014).

Así, se detecta una mayor emisión de señales generalistas o temáticas (musicales y económicas) de grupos de comunicación de ámbito estatal. Estas representan el $60,5 \%$ del total de las emisiones con licencias asignadas, lo que indica un claro desequilibrio con respecto a la emisión de contenidos de proximidad. Es importante remarcar que, aunque parte de estas señales editan ciertos contenidos de proximidad de tipo informativo, el grueso de la emisión se realiza en cadena desde las sedes centrales de producción de estos grupos de comunicación por lo que, en términos de diversidad, el aporte es mínimo. En términos de diversidad geográfica, esto confirma las preocupaciones de McQuail al configurarse un mapa mayoritariamente controlado por grupos de comunicación suprarregionales que dificulta la programación de contenidos diversos y de proximidad.

En paralelo, se emite contenido de origen regional y local (39,5\%). Dos de estas señales, además, lo hacen con presencia en ambas provincias: tanto para toda la comunidad autónoma (7punto7 Radio), como para tres de las islas (Radio ECCA). Así mismo, se detecta un único caso de emisión de tipo provincial (Radio Faycán). El resto de estas señales locales emiten con lógicas programáticas insulares. Estas últimas representan una proporción mínima del espectro asignado $(10,8 \%)$ si bien suponen una oferta variada de contenidos ya que en 17 frecuencias emiten 11 señales independientes. Sin embargo, la diversidad, en términos de equilibrio geográfico, es de nuevo escasa ya que se concentra en las cuatro islas de mayor población. La mayor variedad se detecta en Tenerife (5 señales, 7 licencias), siendo esta la única isla de su provincia con contenidos de proximidad independientes. En la provincia de Gran Canaria, en cambio se emiten señales insulares independientes en todas las islas: Gran Canaria (3 señales, 3 licencias), Fuerteventura ( 2 señales, 4 licencias) y Lanzarote (1 señal, 3 licencias).
Paralelamente, se ha detectado un alto número de emisiones a través de frecuencias no licenciadas e, incluso, no contempladas en el Plan Técnico. Esta práctica es habitual en el mapa radiofónico local en España, bien porque emisoras legales amplifican su potencia de emisión o ubican sus emisiones en espacios no asignados, bien por la ocupación del espacio radioeléctrico por parte de emisoras independientes comerciales locales, radios religiosas, o radios comunitarias (Badillo y Pérez Alaejos en Gallego y García Leiva, 2012; García García, 2013). En este sentido, tanto por la inestabilidad del sector como por la falta de registro y seguimiento por parte de las autonomías, es "complicado establecer el número exacto de emisoras existentes en España y según la fuente el número puede variar" (Pedrero y Badillo en Badillo et al., 2009: 103). En el caso canario, solo se ha podido certificar la existencia de cerca de un centenar de emisiones sin concesión en el conjunto insular ${ }^{10}$. Estas pertenecen, mayoritariamente, a empresas de comunicación de ámbito estatal, algunas que sí poseen concesiones en Canarias (COPE, PRISA, Planeta, o Asociación Radio María) y otras que no (Libertad Digital, Unidad Editorial o Movemos Madrid). Este es el caso de Prensa Ibérica Media que emite a través de ocho frecuencias su señal de radio insular El Día, siendo el único grupo de comunicación de ámbito estatal que programa contenidos de proximidad.

En el caso de las emisiones regionales e insulares, Canarias Difusión, a pesar de poseer concesiones asignadas en el conjunto autonómico, emite a través de otras licencias no reguladas en cuatro de las islas, con mayor presencia en Tenerife. El resto de emisiones insulares sin licencia asignada operan principalmente en las dos capitales, principalmente en Tenerife, si bien se detectan dos casos puntuales de emisión en las islas de La Gomera y Fuerteventura. En este caso, de una señal que opera también con concesión (Radio Sintonía).

Sin concesión de licencias emiten también las radios comunitarias canarias, de las que se localizan un total de ocho, repartidas equilibradamente entre las islas de Tenerife (Radio Ibaute, Radio Geneto, Radio Pimienta y Radio Campus ULL) y Gran Canaria (Radio San Borondón, Radio Carnaval Gran Canaria, Radio Cono Sur, y Radio Guiniguada). La situación de alegalidad de estas radios se repite en el conjunto del estado español como consecuencia de una legislación -Ley General de la Comunicación Audiovisual, 2010- que reconoce tímidamente su existencia pero no les reserva espectro (Meda, 2012: 78). Por ello, estas radios emiten prácticamente a través de internet, donde la distribución reduce costes y no está limitada a licencias otorgadas por la autoridad correspondiente (Fernández-Quijada en Bonet, 2016: 173), aunque algunas de ellas también radian su señal en FM. Es importante incluirlas en el análisis porque constituyen un aporte a la diversidad audiovisual del

\footnotetext{
A pesar de que históricamente la cifra ofrecida en Canarias por la Asociación Española de Radiodifusión ronda las 400, se ha optado por incluir solo en el estudio aquellas emisiones cuya existencia se ha podido certificar a través de la información publicada por las empresas de comunicación mencionadas.
} 
mapa radiofónico canario en términos de diversidad de fuentes pero también de contenidos. En 2019, seis de ellas articularon la Red de Radios Libres y Comunitarias de Canarias con el objetivo de compartir contenidos, contribuir a la democratización y crear un informativo común y una televisión online gestionada conjuntamente (ReMC, 2019).

\subsection{El mapa televisivo local}

El proceso de configuración del mapa de Televisión Digital Terrestre (TDT) local en España se configuró sobre la preeminencia de los operadores privados, considerados "el eje de la nueva televisión local que se ha diseñado con la digitalización” (Corominas et al., 2007: 89). A esto se sumó "la notable presencia de grandes grupos de comunicación y la tendencia a la concentración de la propiedad" (Fernández Alonso et al., 2007: 218). En este sentido, las concesiones otorgadas identificaron dos grandes categorías de sociedades concesionarias: los principales grupos de comunicación de ámbito estatal (como PRISA, Libertad Digital, Prensa Ibérica Media o Vocento) y los concesionarios de ámbito autonómico (Corominas et al., 2007; Guimerà i Orts, 2011). En toda España los concursos estuvieron plagados de cuestionamientos a los gobiernos autonómicos, encargados de otorgar las licencias, que fueron acusados de favorecer intereses privados de algunos agentes (Fernández Alonso et al., 2007; Ortega, 2009; Badillo, 2010). El caso canario no fue una excepción. Aunque el concurso inicial se resolvió en 2007, fue anulado por el Tribunal Superior de Justicia de Canarias. Tras un proceso jurídico extenso y la convocatoria de nuevos concursos, el mapa de TDT local actual dista, y mucho, de las concesiones iniciales, en línea con lo ocurrido en el resto de España donde la presencia de los grupos de ámbito estatal en los mapas de TDT local se ha diluido con el tiempo (Badillo, 2010; Cañedo, 2018).

En la actualidad, el Registro Público de Concesiones reconoce 32 concesiones activas (29 locales y tres insulares). Estas se reparten entre un total de 21 sociedades, con un alto predominio de los operadores privados en la obtención de licencias $(85,7 \%)$, algunos de los cuales también están presentes en el escenario de la radio local (Anexo II). Si se atiende al reparto geográfico de estas concesiones, de nuevo se evidencia la concentración en las islas capitales y el desequilibrio entre islas. En Gran Canaria se ubican 11 de las licencias $(35,5 \%)$ mientras que en Tenerife, la otra isla capital, se detectan cinco concesiones de TDT 1ocal así como las tres únicas concesiones insulares (dos de gestión privada y una pública). Fuerteventura, por su parte, aglutina seis concesiones $(19,3 \%)$ mientras que en La Palma, El Hierro y Lanzarote se identifican tres, dos y una, respectivamente.

Según la naturaleza de las sociedades concesionarias, todas tienen su domicilio social en Canarias a excepción de Telelínea Local, domiciliada en Madrid, que posee cinco concesiones en diferentes islas. Por tanto, la presencia de empresas canarias en la gestión de licencias de televisión local en Canarias es preeminente. Respecto a su propiedad, solo una de las sociedades de titularidad privada depende de un grupo de comunicación de ámbito estatal, es el caso de Grupo de Medios de Tenerife, que depende de Prensa Ibérica Media, grupo editor de dos de las cabeceras de prensa diarias de la región, presente también en la radio local -aunque sin licencia-, y que opera en Tenerife una licencia insular de TDT local de gestión privada. Este grupo representa, en el caso canario, una realidad presente en el conjunto del panorama estatal: el de la concentración multimedia en el mercado local (Bustamante, 2015). La otra licencia insular privada la opera un grupo local, con presencia exclusivamente en las concesiones televisivas, Canal 8 Medios Audiovisuales S.L., que también posee una licencia local.

La tercera concesión de licencia insular se localiza también Tenerife, si bien su gestión es tarea del Cabildo insular y, por tanto, pública. Las otras dos licencias asignadas a operadores públicos son de tipo local y se localizan en Gran Canaria. Son la del Ayuntamiento de Mogán y la del Consorcio Sur Gran Canaria para la TDT Local Demar, que aglutina a seis ayuntamientos de la isla ${ }^{11}$ para la emisión de la señal conjunta Este Canal. Estas corporaciones poseen concesiones tanto en el mapa radiofónico como en el televisivo lo que les permite articular contenidos de proximidad por esta doble vía. Esta dinámica también la replican las empresas privadas Radio Gigante S.L. y Transformaciones y Servicios S.L. que poseen concesiones en ambos espacios, si bien su actividad se concentra en Tenerife.

El resto de adjudicatarios operan entre una y tres licencias. Los que poseen varias, lo hacen mayoritariamente en la misma isla (Publikeira S.L. o Diario independiente de Canarias S.L.) aunque se detectan casos de empresas con concesiones en islas contiguas (Las Arenas Canal Canarias S.L., Asociación Ojos Solidarios ONG o U.T.E. Estudios Ópalo-Torrabonaf Sport-7 Cantabria Digital TV). Se destaca que, en este último caso, los contenidos emitidos no son los mismos en ambos espacios insulares. 
Figura 4. Canarias: contenidos en emisión de TDT local a través de emisiones con concesión de licencia (por tipo de licencia). Elaboración propia a partir del Registro Público de Concesiones, de la base de datos SABI y de la información corporativa facilitada por cada medio.

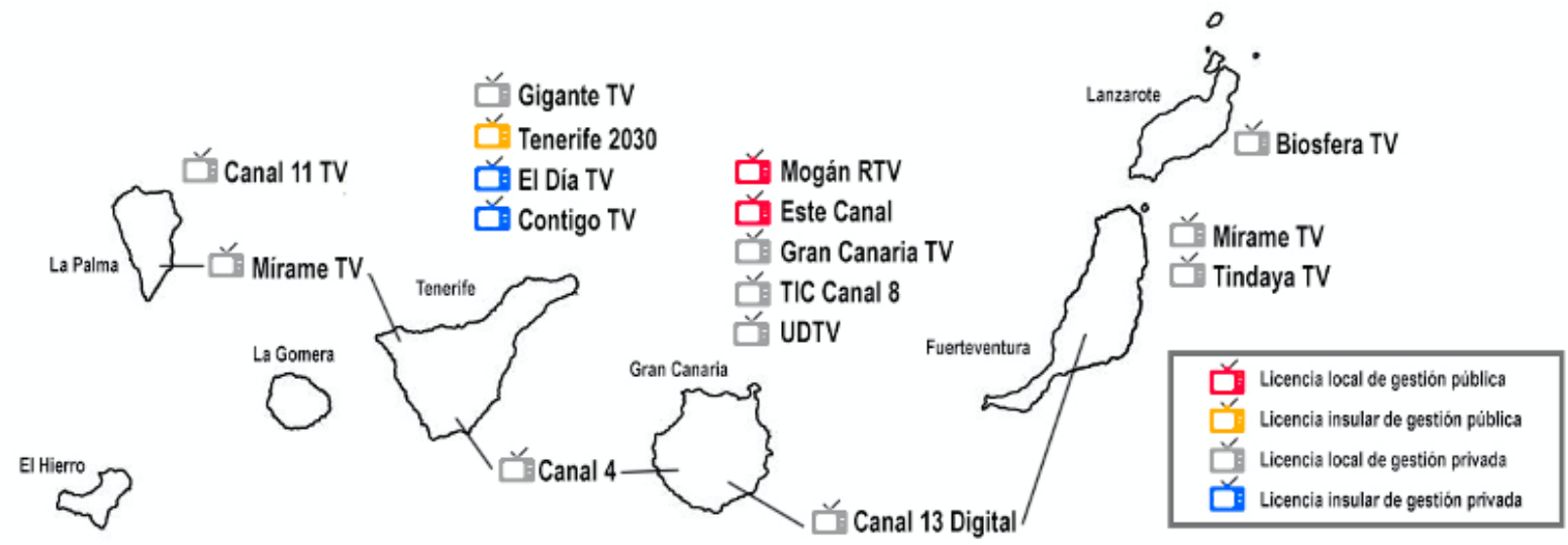

Respecto a los contenidos, todos los canales activos son producidos en la región lo que significa un aporte evidente al espacio comunicativo en términos de diversidad. Se destaca como positivo que las tres señales públicas programan contenidos de proximidad (local e insultar) siguiendo las lógicas del servicio público. Si bien, como ocurre en otros territorios (Monedero Morales en Chaparro, 2014; Guimerà i Orts et al., 2017), el sector de TDT local pública es minoritario.

La mayor variedad en la oferta se localiza en la isla de Gran Canaria donde se emiten hasta siete señales diferentes, dos de ellas públicas locales. De este total, cuatro complementan su emisión a través de las ondas de radio: Mogán RTV, Este Canal, UDTV y Canal 4. Esta última emite también en la isla de Tenerife. A ella se suman, en esta isla, la emisión de dos señales locales de gestión privada Mírame TV y Gigante TV, presente en el mapa radiofónico; y las tres señales insulares -dos de gestión privada (El Día TV y Contigo TV) y una pública (Tenerife 2030)-. En el resto de islas, solo se ha podido certificar emisión a través de dos concesiones de La Palma (Canal 11 $T V$ y Mírame $T V$ ). Por su parte, las señales locales Biosfera $T V$ y Tindaya $T V$ emiten para Lanzarote y Fuerteventura, respectivamente. En esta isla también emiten Mirame TV y Canal 13 Digital, dos señales con emisiones en otras islas.

Como ocurre en el mapa radiofónico, se ha detectado la existencia de otros canales que podrían operar en la TDT local canaria sin que se haya podido certificar que disponen de licencia asignada en el espacio que ocupan. Este es el caso de Mírame TV, que podría emitir en más frecuencias de las mencionadas, o de Canal $10 T V$ (Tenerife). Además, existe un caso de televisión local, Lancelot TV (Lanzarote) que emite únicamente a través de internet. Respecto a las televisiones comunitarias, en Canarias no se detecta la emisión a través del espectro de ninguna de ellas, en línea con lo que ocurre en el resto del mapa audiovisual español donde su presencia es puntual o inexistente (Badillo, 2003;
Bustamante, 2008; Badillo, 2010). Al igual que ocurre con las radios, como consecuencia del desamparo legal que sufren estos medios (Bustamante, 2008; Barranquero y Meda, 2015).

\section{Conclusiones}

Los patrones identificados en el mapa de radiotelevisión local en Canarias señalan que la diversidad externa se configura en términos de insularidad, poniendo en evidencia las vinculaciones entre el modelo territorial regional y la definición de su mapa de radiotelevisión local. El análisis da cuenta de un espacio comunicativo definido tanto por las lógicas insulares como por la doble capitalidad, en el que el desbalance entre islas y la preeminencia de los operadores de titularidad privada se muestra como la característica más evidente.

El desequilibrio se evidencia en el hecho de que de las 229 concesiones de radiotelevisión local asignadas en el territorio, la mayor parte se ubican en Tenerife $(35,8 \%)$ y Gran Canaria $(29,7 \%)$, las islas capitales. Estas islas son, así mismo, las que presentan una mayor variedad tanto en el tipo de licencias concedidas como en la naturaleza de las sociedades concesionarias. En el término opuesto, El Hierro y La Gomera, que entre ambas islas aglutinan poco más del 6\% de las licencias. En el caso de La Gomera, además, se destaca la ausencia de asignación de concesiones de licencias de TDT local, siendo la única isla que no dispone de ellas.

Si se analizan las características de los concesionarios de licencias de tipo local, la única característica compartida entre islas es la presencia mayoritaria de operadores de titularidad privada gestionados por grupos de comunicación de ámbito estatal y regional en el mapa radiofónico. Una pauta que, sin embargo, no se repite en el ámbito de la TDT local donde no es posible identificar un patrón común al conjunto insular. 
Al hilo del concepto de diversidad geográfica, es posible concluir que este mapa evidencia que Canarias cuenta con medios de comunicación propios diversos; articulados bien a través de grupos de comunicación regional o independientes, siendo mayoritaria la presencia de los primeros (66 de las concesiones frente a 47). Además, es importante destacar la existencia de operadores locales que emiten tanto en el sector radiofónico como en el televisivo. Estos agentes, tanto de gestión privada como pública (minoritarios), permiten articular redes de comunicación de proximidad de tipo regional (Canarias Difusión o Faycán), insular (Tele Canal 4 Tenerife S.A.U. o Corporación Lanzaroteña de Medios) o local (Mogán RTV). Esto es especialmente positivo para la diversidad ya que se constituyen como los únicos capaces de hacer frente al dominio del espacio por parte de los grupos de comunicación de ámbito estatal.

Figura 5: Canarias: concesionarios de licencia local de radiodifusión FMy de TDT local (por isla). Elaboración propia a partir del Registro Público de Concesiones, de la base de datos SABI y de la información corporativa facilitada por cada medio.

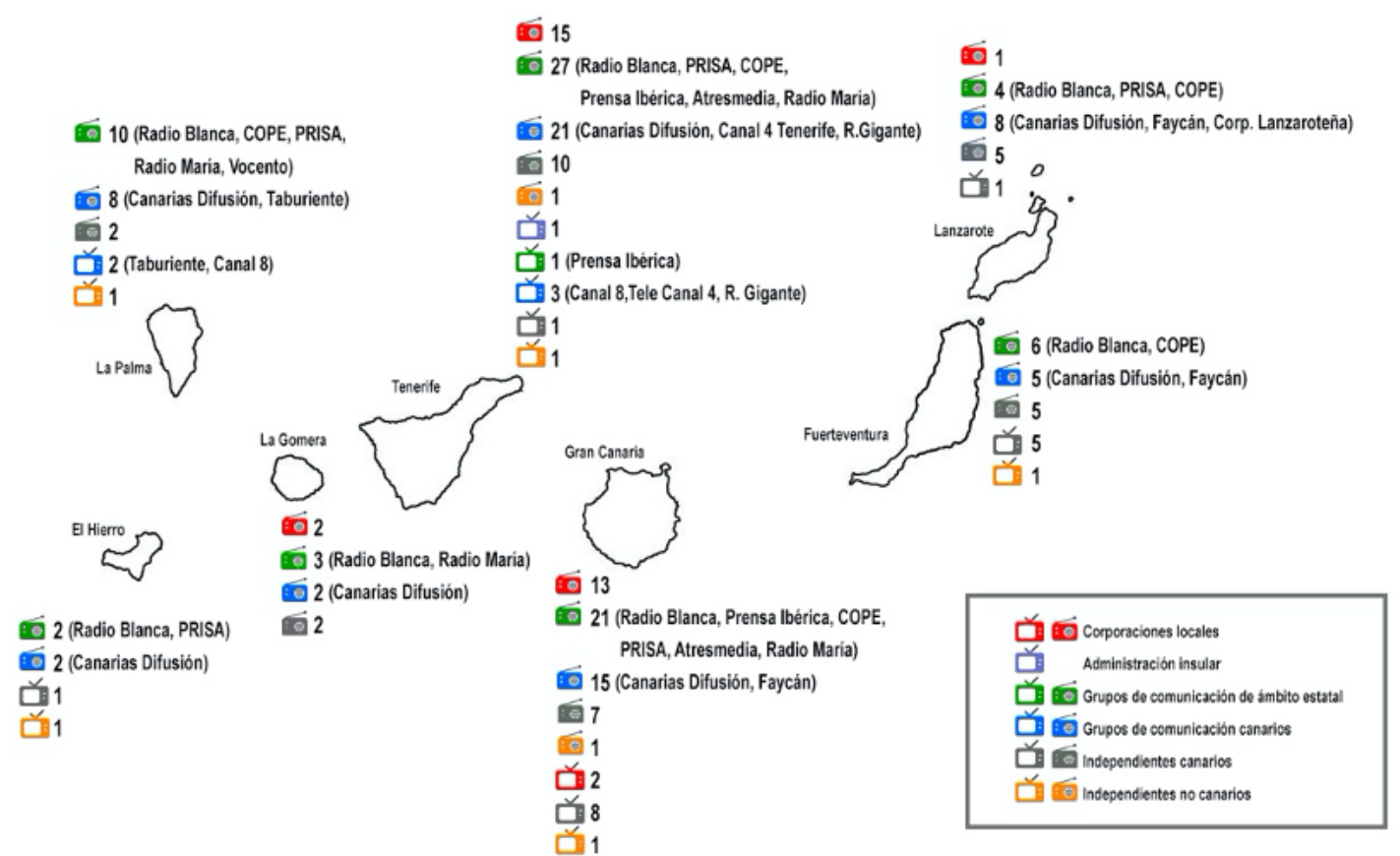

Si se atiende al contenido emitido, las conclusiones son diferentes en función del sector. En el mapa radiofónico, la oferta de contenidos locales no parece suficiente para suplir a la ofrecida por los medios de ámbito estatal que dominan el $60,5 \%$ de la emisión con licencia, volumen al que se han de sumar sus emisiones ilegales. Su personalización para el territorio es más bien escasa lo que permite afirmar, en línea con lo que señalaba McQuail, que no prestan la atención necesaria al contenido regional. En la TDT local, las dinámicas cambian, siendo mayoritaria la emisión de contenidos de proximidad. Si bien, el análisis permite concluir que en el caso canario, como en el resto de España, las promesas de pluralidad que traía consigo la digitalización no han cristalizado: son pocas las señales emitiendo y tan solo en Gran Canaria y Tenerife operan más de dos señales diferenciadas. Por ello, no se puede decir que exista una competencia real en el sector.

La investigación desarrollada en el presente artículo permite llenar un vacío en el estudio de la estructura de los espacios de comunicación locales desde la perspectiva de la diversidad. Los resultados confirman que las preocupaciones reflejadas por
McQuail, y retomadas por el grupo de investigación Diversidad Audiovisual, están vigentes. En un sector, el del audiovisual, que tiende a la concentración, la principal propuesta para articular un aporte mayor a la diversidad audiovisual pasa por desarrollar políticas de comunicación públicas que tengan en cuenta la importancia de la comunicación local. En el caso canario, sería recomendable que las administraciones públicas, locales e insulares, apuesten de manera decidida por el desarrollo de medios de comunicación propios para hacer frente al predominio de las emisiones de los operadores privados. Así mismo, habría que fortalecer el papel de los medios comunitarios que existen en la región, los cuales ya han comenzado a articularse para hacer frente a la poca oferta de comunicación de proximidad en el territorio. La colaboración entre el sector público y la sociedad civil se hace indispensable para que los ciudadanos canarios reciban contenidos de proximidad editados desde las lógicas del servicio público de radiodifusión. Respecto a los operadores privadores con ánimo de lucro, se debería llevar a cabo una fiscalización continuada de sus obligaciones como emisores y sancionar la ocupación ilegal del dominio público radioeléctrico. 
Como futuras investigaciones se sugiere ampliar el análisis a otros espacios de comunicación regional definidos por su insularidad, con el fin de validar la dimensión de la insularidad como un elemento definitorio del modelo de radiodifusión desarrollado en las regiones-archipiélago. Así mismo, se su- giere replicar el diseño metodológico de la presente investigación en otras comunidades autónomas de España para completar los estudios ya existentes y establecer, en términos de diversidad, similitudes y diferencias en el conjunto estatal del mapa de radiotelevisión local.

\section{Referencias bibliográficas}

Albornoz, L.A. \& García Leiva, M.T. (eds.). (2012). La televisión digital terrestre. Experiencias nacionales y diversidad en Europa, América y Asia. La Crujía Ediciones.

Albornoz, L.A. \& García Leiva, M.T. (eds.). (2017a). El audiovisual en la era digital. Políticas y estrategias para la diversidad. Cátedra.

Albornoz, L.A. \& García Leiva, M.T. (eds.). (2017b). Diversidad e industria audiovisual: el desafío cultural del siglo $X X I$. Fondo de Cultura Económica.

Arboledas, L. (2009). Clientelismo y concentración en la radio española. Comparación entre cuatro comunidades autónomas. Revista Latina de Comunicación Social 64, 909-925. 10.4185/RLCS-64-2009-870-909-925

Arboledas, L., \& Bonet, M. (2013). Radio on the Iberian Peninsula: Autarky, revolution and convergence. International Communication Gazette 75 (2), 205-224 https://doi.org/10.1177/1748048512465557

Badillo, Á.(2003). La desregulación de la televisión local en España: el caso de Castilla y León. [Tesis doctoral. Universitat Autònoma de Barcelona] https://bit.ly/3bAR3HU

Badillo, Á., Pedrero, L.M., \& Fuertes, M. (coords.). (2009). La industria audiovisual y publicitaria en Castilla y León. https://bit.ly/2ZfYW01

Badillo, Á. (2010). Competencia, crisis, digitalización y la reordenación de la televisión de proximidad en España. Quaderns del CAC 35, 22-34.

Badillo, Á. (2011). Modelos de clivaje público-privado de la televisión subnacional en España. adComunica. Revista de Estrategias, Tendencias e Innovación en Comunicación 1, 63-81.

Barranquero, A. \& Meda, M. (2015). Los medios comunitarios y alternativos en el ciclo de protestas ciudadanas desde el 15M. Athenea Digital 15 (1), 139-170. http://dx.doi.org/10.5565/rev/athenea.1385

Bonet, M. \& Arboledas, L. (2012). The European Exception: Historical Evolution of Spanish Radio as a Cultural Industry. Media International Australia 141, 38-48. https://doi.org/10.1177/1329878X1114100106

Bonet, M. (coord.). (2016). El imperio del aire. Espectro radioeléctrico y radiodifusión. Editorial UOC.

Bustamante, E. (2008). La televisión digital terrestre en España. Por un sistema televisivo de futuro acorde con una democracia de calidad. Documento de trabajo 129/2008. Fundación Alternativas.

Bustamante, E. (2015). Historia de la radio y la televisión en España. Una asignatura pendiente de la democracia. Gedisa.

Cañedo, A. (2018). Televisión del Principado de Asturias: dinamización y diversidad en el sector audiovisual asturiano (2005-2015). [Tesis doctoral. Universidad Carlos III de Madrid]. https://bit.ly/3h6J4n5

Cañedo, A. (2019). Austeridad versus diversidad: la producción de contenidos informativos en Televisión del Principado de Asturias. Communication \& Society 32 (4), 77-92. https://doi.org/10.15581/003.32.4.77-92

Chaparro, M. (1998). Radio pública local. Fragua.

Chaparro, M. (ed.). (2014). Medios de proximidad: participación social y políticas públicas. de Gálibo / iMedea / COMAndalucía.

Corominas, M., Bonet, M., Fernández Alonso, I., Guimerà i Orts, J.Á, Sanmartín Navarro, J., \& Blasco Gil, J.J. (2007). Televisión digital terrestre local (TDT-L) en España: los concesionarios privados. Zer 22, 69-95.

Fernández Alonso, I., Corominas, M., Bonet, M., Guimerà i Orts, J.À., \& Sanmartín Navarro, J. (2007). Políticas de Implantación de la TDT local en España (2005-2006): los casos de las Comunidades Autónomas de Islas Baleares, Madrid, Región de Murcia, Comunidad Valenciana, Galicia, Cataluña y Aragón. Observatorio (OBS*) Journal 1, 205224. https://doi.org/10.15847/obsOBS11200746

Fernández-Sande, M. \& Gallego, J.I. (2019). Challenges for Radio in the Digital Era: Diversity, Innovation and Policies. In J.I. Gallego, M. Fernández-Sande \& N. Limón (ed.). Trends in Radio Research. Diversity, Innovation and Policies, pp. 1-14.

Gallego, J.I., \& García Leiva, M.T. (coords.). Sintonizando el futuro. Radio y producción sonora en el siglo XXI. Instituto RTVE.

García Castillejo, Á. (2015). Radio y televisión local. Ciudad y ciudadanía en los medios audiovisuales. Revista Internacional de Comunicación y Desarrollo 4, 119-132. https://doi.org/10.15304/ricd.1.4.3478

García García, J. (2013). Transformaciones en el tercer sector: el caso de las radios comunitarias en España. adCcomunica, Revista de Estrategias, Tendencias e Innovación en Comunicación 5, 111-131. http://dx.doi.org/10.6035/ 2174-0992.2013.5.8 
Guimerà i Orts, J.À. (2011). Políticas de TDT y configuración del mapa televisivo autonómico digital en la Comunidad Autónoma Vasca (2002-2007). Zer 16 (31), 13-30.

Guimerà i Orts, J.À., Monedero Morales, C.R., \& Martori Muntsant, A. (2017). Digitalización, crisis económica y televisión pública local en España. Los casos de Andalucía y Cataluña (2010-2015). Revista Latina de Comunicación Social, 72, 574-589. http://dx.doi.org/10.4185/RLCS-2017-1180

Marzal, J., \& Casero, A. (2008). La investigación sobre la televisión local en España: nuevas agendas ante el reto de la digitalización. Zer 13 (25), 83-106.

McQuail, D. (1998). La acción de los medios. Los medios de comunicación y el interés público. Amorrortu.

Meda, M. (2012). Del arte de cambiar para que todo siga igual: el Tercer Sector de la Comunicación y la Ley General Audiovisual en España. Commons 1 (1), 58-84. http://dx.doi.org/10.25267/COMMONS.2012.v1.i1.05

Moragas, M., Garitaonandía, C., \& López, B. (eds.). (1999). Televisión de proximidad en Europa. Experiencias de descentralización en la era digital. Universitat Autònoma de Barcelona.

Morales Mato, G. (2001). Las Islas Canarias ¿una región aislada?. Boletín de la A.G.E 32, 155-175.

Napoli, P. (1999). Deconstructing the Diversity Principle. Journal of Communication 49(4), 7-34. https://doi.org/10.1111/j.1460-2466.1999.tb02815.x

Nerekan Umaran, A., Casado del Río, M.Á., Zallo, R., \& Miguel de Bustos, J.C. (eds.). (2015). Comunicación de proximidad: cada vez más lejos. Marco, experiencias y regulación. Universidad del País Vasco.

Ortega Mohedano, F. (2009). La televisión de proximidad en España. Procesos concesionales, análisis de la población y PIB. Revista Latina de Comunicación Social 12 (64), 585-601. 10.4185/RLCS-64-2009-847-585-601

Ramos Pérez, D. (2005). Modelo territorial, movilidad insular y sostenibilidad en Canarias: una reflexión crítica. Boletín de la A.G.E. 40, 245-268.

ReMC (2019). Las radios canarias crean una red de emisoras libres y comunitarias. https://bit.ly/35eGQ2Q

SGAE (2019). Anuario SGAE de las artes escénicas, musicales y audiovisuales 2019. https://bit.ly/3bykBG4

Stirling, A. (1998). On the economics and analysis of diversity. Working Paper 28. University of Sussex.

Stirling, A. (2007). A general framework for analysing diversity, in science, technology and society. Journal of the Royal Society Interface 4, 707-719, 10.1098/rsif.2007.0213

UNESCO (2001). Declaración de la UNESCO sobre diversidad cultural. UNESCO.

UNESCO (2005). Convención sobre la protección y la promoción de la diversidad de las expresiones culturales. UNES$\mathrm{CO}$.

UNESCO (2013). Declaración de Hangzhou. UNESCO.

Yin, R.K. (2003). Case Study research. Design and Methods. Sage.

\section{Anexos}

\section{Anexo I. Canarias: concesionarios de licencias para la emisión de emisoras municipales en FM.}

Elaboración propia a partir del Registro Público de Concesiones y de la información corporativa facilitada por los Ayuntamientos y sus medios.

\begin{tabular}{|l|l|l|}
\hline \multicolumn{1}{|c|}{ Ayuntamiento concesionario } & \multicolumn{1}{c|}{ Isla } & \multicolumn{1}{c|}{ Canal en emisión } \\
\hline Ayuntamiento de Gáldar & Gran Canaria & Radio Gáldar \\
\hline Ayuntamiento de Ingenio & Gran Canaria & Radio 10 Ingenio \\
\hline Ayuntamiento de San Bartolomé de Tirajana & Gran Canaria & Radio Dunas \\
\hline Ayuntamiento de Valleseco & Gran Canaria & Radio Valleseco \\
\hline Ayuntamiento de Telde & Gran Canaria & Inactiva \\
\hline Ayuntamiento de Villa de Agüimes & Gran Canaria & Radio Agüimes \\
\hline Ayuntamiento de Agaete & Gran Canaria & Radio Agaete \\
\hline Ayuntamiento de Santa Lucía de Tirajana & Gran Canaria & Radio Tagoror \\
\hline Ayuntamiento de Valsequillo & Gran Canaria & Radio Valsequillo \\
\hline Ayuntamiento de San Nicolás de Tolentino & Gran Canaria & Radio La Aldea \\
\hline Ayuntamiento de Santa Brígida & Gran Canaria & Inactiva \\
\hline Ayuntamiento de Mogán & Gran Canaria & Radio Mogán \\
\hline Ayuntamiento de Arucas & Gran Canaria & Radio Arucas \\
\hline Ayuntamiento de Tegueste & Tenerife & No consta \\
\hline Ayuntamiento de Tacoronte & Tenerife & No consta \\
\hline
\end{tabular}




\begin{tabular}{|l|l|l|}
\hline Ayuntamiento de Arico & Tenerife & Radio Arico \\
\hline Ayuntamiento de Agulo & Tenerife & Radio Agulo \\
\hline Ayuntamiento de la Matanza de Acentejo & Tenerife & No consta \\
\hline Ayuntamiento de El Sauzal & Tenerife & No consta \\
\hline Ayuntamiento de San Miguel & Tenerife & Radio Municipal San Miguel de Abona \\
\hline Ayuntamiento del Rosario & Tenerife & Onda Joven El Rosario \\
\hline Ayuntamiento Valle Gran Rey & Tenerife & Inactiva \\
\hline Ayuntamiento de Villa de Adeje & Tenerife & Radio Sur Adeje \\
\hline Ayuntamiento de Villa Hermigua & Tenerife & Inactiva \\
\hline Ayuntamiento de Los Realejos & Tenerife & Radio Realejos \\
\hline Ayuntamiento de Guía de Isora & Tenerife & Radio Isora \\
\hline Ayuntamiento de Garachico & Tenerife & Inactiva \\
\hline Ayuntamiento de la Guancha & Tenerife & Radio La Guancha \\
\hline Ayuntamiento de Vallehermoso & La Gomera & No consta \\
\hline Ayuntamiento de San Sebastián de La Gomera & La Gomera & Radio Ipalán \\
\hline Ayuntamiento de Teguise & Lanzarote & Radio Municipal de Teguise \\
\hline
\end{tabular}

\section{Anexo I1: Canarias: concesionarios de licencia para la emisión de emisoras privadas en FM}

* Nota: imposibilidad de certificar la continuidad de la emisión en la actualidad. Elaboración propia a partir del Registro Público de Concesiones, de la base de datos SABI y de la información corporativa facilitada por cada empresa/medio.

\begin{tabular}{|c|c|c|c|c|c|c|c|c|c|c|c|}
\hline \multirow{2}{*}{ Sociedad concesionaria } & \multirow{2}{*}{$\begin{array}{l}\text { Grupo de comu- } \\
\text { nicación }\end{array}$} & \multicolumn{2}{|c|}{$\begin{array}{l}\text { Número de } \\
\text { licencias }\end{array}$} & \multirow{2}{*}{ 国 } & \multirow{2}{*}{ 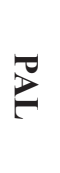 } & \multirow{2}{*}{$\begin{array}{l}2 \\
0 \\
3\end{array}$} & \multirow{2}{*}{ 茎 } & \multirow{2}{*}{$\hat{\partial}$} & \multirow{2}{*}{ 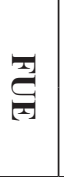 } & \multirow{2}{*}{ 妾 } & \multirow{2}{*}{$\begin{array}{l}\text { Señales en } \\
\text { emisión }\end{array}$} \\
\hline & & Total & $\begin{array}{c}\text { Por } \\
\text { señal }\end{array}$ & & & & & & & & \\
\hline \multirow{2}{*}{ Kiss Radio S.A. (Madrid) } & \multirow{2}{*}{$\begin{array}{l}\text { Radio Blanca (Ma- } \\
\text { drid) }\end{array}$} & \multirow{2}{*}{29} & 19 & 1 & 2 & 2 & 6 & 4 & 2 & 2 & Kiss FM \\
\hline & & & 10 & & & & 4 & 4 & 2 & & Hit FM \\
\hline $\begin{array}{l}\text { Canarias Difusión S.L. } \\
\text { (Gran Canaria) }\end{array}$ & $\begin{array}{l}\text { Canarias Difusión } \\
\text { S.L. (Gran Cana- } \\
\text { ria) }\end{array}$ & 29 & 29 & 2 & 3 & 2 & 10 & 5 & 4 & 3 & $\begin{array}{l}\text { 7punto7 Ra- } \\
\text { dio }\end{array}$ \\
\hline $\begin{array}{l}\text { Faycán Publicidad (Gran } \\
\text { Canaria) }\end{array}$ & $\begin{array}{l}\text { Faycán Red de } \\
\text { Emisoras (Gran } \\
\text { Canaria) }\end{array}$ & 12 & 12 & & & & & 10 & 1 & 1 & Radio Faycán \\
\hline \multirow{2}{*}{$\begin{array}{l}\text { Radio Popular S.A. Cadena } \\
\text { de Ondas Popular (Madrid) }\end{array}$} & \multirow{2}{*}{ COPE (Madrid) } & \multirow{2}{*}{11} & 5 & & 1 & & 2 & 1 & & 1 & COPE \\
\hline & & & 6 & & 1 & & 2 & 2 & 1 & & Cadena 100 \\
\hline \multirow{2}{*}{$\begin{array}{l}\text { Tele Canal } 4 \text { Tenerife } \\
\text { S.A.U. (Tenerife) }\end{array}$} & \multirow{2}{*}{$\begin{array}{l}\text { Canal } 4 \text { Tenerife } \\
\text { (Tenerife) }\end{array}$} & \multirow[t]{2}{*}{10} & 2 & & & & 2 & & & & $\begin{array}{l}\text { Canal } 4 R a- \\
\text { dio* }\end{array}$ \\
\hline & & & 8 & & & & 8 & & & & EsRadio \\
\hline \multirow{6}{*}{$\begin{array}{l}\text { Sociedad Española de Ra- } \\
\text { diodifusión S.L. (Madrid) }\end{array}$} & \multirow{6}{*}{ PRISA (Madrid) } & \multirow{6}{*}{8} & 3 & & & & 1 & 1 & & 1 & $\operatorname{Los} 40$ \\
\hline & & & 1 & & & & & 1 & & & SER \\
\hline & & & 1 & & 1 & & & & & & $\begin{array}{l}\text { Radio La } \\
\text { Palma }\end{array}$ \\
\hline & & & 1 & & & & 1 & & & & $\begin{array}{l}\text { Radio Club } \\
\text { Tenerife }\end{array}$ \\
\hline & & & 1 & & & & 1 & & & & No consta \\
\hline & & & 1 & & & & 1 & & & & Cadena Dial \\
\hline
\end{tabular}




\begin{tabular}{|c|c|c|c|c|c|c|c|c|c|c|c|}
\hline \multirow{4}{*}{$\begin{array}{l}\text { Radio Club de Canarias } \\
\text { (Tenerife) }\end{array}$} & \multirow{4}{*}{ PRISA (Madrid) } & \multirow{4}{*}{8} & 2 & & & & 1 & 1 & & & Cadena Dial \\
\hline & & & 3 & & & & 3 & & & & $\operatorname{Los} 40$ \\
\hline & & & 2 & & & & 2 & & & & $\begin{array}{l}\text { Radio Club } \\
\text { Tenerife }\end{array}$ \\
\hline & & & 1 & 1 & & & & & & & $\begin{array}{l}\text { SER Radio } \\
\text { Garoe }\end{array}$ \\
\hline \multirow{4}{*}{$\begin{array}{l}\text { Editorial Prensa Canaria } \\
\text { S.L. (Gran Canaria) }\end{array}$} & \multirow{4}{*}{$\begin{array}{l}\text { Prensa Ibérica Me- } \\
\text { dia (Barcelona) }\end{array}$} & \multirow{4}{*}{5} & 1 & & & & & 1 & & & COPE \\
\hline & & & 2 & & & & & 2 & & & SER \\
\hline & & & 1 & & & & & 1 & & & $\begin{array}{l}\text { Los } 40 \text { Clas- } \\
\text { sic }\end{array}$ \\
\hline & & & 1 & & & & & 1 & & & No consta \\
\hline \multirow{2}{*}{$\begin{array}{l}\text { Radio CIT Tenerife S.L. } \\
\text { (Tenerife) }\end{array}$} & \multirow{2}{*}{---} & \multirow{2}{*}{5} & 2 & & & & 2 & & & & Capital Radio \\
\hline & & & 3 & & & & 3 & & & & No consta \\
\hline $\begin{array}{l}\text { Producciones Radio Te- } \\
\text { levisiva Taburiente S.L. } \\
\text { (Tenerife) }\end{array}$ & $\begin{array}{l}\text { Producciones } \\
\text { Radio Televisiva } \\
\text { Taburiente (Tene- } \\
\text { rife) }\end{array}$ & 5 & 5 & & 5 & & & & & & EsRadio \\
\hline \multirow{2}{*}{ RK20 S.L. (Madrid) } & \multirow{2}{*}{$\begin{array}{l}\text { Radio María (Ma- } \\
\text { drid) }\end{array}$} & \multirow{2}{*}{5} & 3 & & 1 & & 1 & 1 & & & Radio María \\
\hline & & & 2 & & 1 & 1 & & & & & No consta \\
\hline \multirow{2}{*}{$\begin{array}{l}\text { Editorial Lancelot (Lanza- } \\
\text { rote) }\end{array}$} & \multirow{2}{*}{$\begin{array}{l}\text { Corporación Lan- } \\
\text { zaroteña de Me- } \\
\text { dios (Lanzarote) }\end{array}$} & \multirow[t]{2}{*}{4} & 3 & & & & & & & 3 & $\begin{array}{l}\text { Lancelot Ra- } \\
\text { dio }\end{array}$ \\
\hline & & & 1 & & & & & & & 1 & Radio Marca \\
\hline $\begin{array}{l}\text { Radio ECCA Fundación } \\
\text { Canaria (Gran Canaria) }\end{array}$ & --- & 4 & 4 & & 2 & & & 1 & 1 & & Radio ECCA \\
\hline $\begin{array}{l}\text { Fuerteventura Media S.L. } \\
\text { (Fuerteventura) }\end{array}$ & --- & 3 & 3 & & & & & & 3 & & $\begin{array}{l}\text { Radio Sinto- } \\
\text { nía }\end{array}$ \\
\hline $\begin{array}{l}\text { Compañía Canaria de Emi- } \\
\text { siones S.L. (Lanzarote) }\end{array}$ & --- & 3 & 3 & & & & & & & 3 & Onda Cero \\
\hline \multirow{2}{*}{ Radio Publi S.L. (Madrid) } & \multirow{2}{*}{ Vocento (Vizcaya) } & \multirow{2}{*}{3} & 2 & & 2 & & & & & & COPE \\
\hline & & & 1 & & 1 & & & & & & Cadena 100 \\
\hline Uniprex S.A.U. (Madrid) & $\begin{array}{l}\text { Atresmedia (Ma- } \\
\text { drid) }\end{array}$ & 2 & 2 & & & & 1 & 1 & & & Onda Cero \\
\hline \multirow{2}{*}{$\begin{array}{l}\text { Radio Las Palmas S.A. } \\
\text { (Gran Canaria) }\end{array}$} & \multirow[t]{2}{*}{---} & \multirow[t]{2}{*}{2} & 1 & & & & & 1 & & & $\begin{array}{l}\text { Inolvidable } \\
F M\end{array}$ \\
\hline & & & 1 & & & & & 1 & & & EsRadio \\
\hline \multirow{2}{*}{$\begin{array}{l}\text { Archipiélago On Air } \\
\text { S.L.(Tenerife) }\end{array}$} & \multirow{2}{*}{---} & \multirow{2}{*}{2} & 1 & & & & 1 & & & & Europa FM \\
\hline & & & 1 & & & 1 & & & & & No consta \\
\hline \multirow{2}{*}{$\begin{array}{l}\text { Multipropiedad de Tenerife } \\
\text { S.A. (Tenerife) }\end{array}$} & \multirow[t]{2}{*}{---} & \multirow[t]{2}{*}{2} & 1 & & & & 1 & & & & $\begin{array}{l}\text { Los } 40 \text { Clas- } \\
\text { sic }\end{array}$ \\
\hline & & & 1 & & & 1 & & & & & Cadena Dial \\
\hline $\begin{array}{l}\text { Radio Atlántico S.L.U. } \\
\text { (Gran Canaria) }\end{array}$ & --- & 1 & 1 & & & & & 1 & & & COPE \\
\hline $\begin{array}{l}\text { FM Radio Canarias S.L. } \\
\text { (Tenerife) }\end{array}$ & COPE (Madrid) & 1 & 1 & & & & & & 1 & & COPE \\
\hline $\begin{array}{l}\text { Radio Tamarán FM } 1995 \\
\text { S.L. (Gran Canaria) }\end{array}$ & --- & 1 & 1 & & & & & 1 & & & Tamarán FM \\
\hline $\begin{array}{l}\text { Clan de Medios, Comuni- } \\
\text { cación y Marketing (Gran } \\
\text { Canaria) }\end{array}$ & --- & 1 & 1 & & & & & 1 & & & No consta \\
\hline $\begin{array}{l}\text { Comunicaciones Los Puen- } \\
\text { tes S.L. (Lanzarote) }\end{array}$ & --- & 1 & 1 & & & & & & & 1 & COPE \\
\hline $\begin{array}{l}\text { Agrupación Radiofónica } \\
\text { S.A. (La Coruña) }\end{array}$ & --- & 1 & 1 & & & & & 1 & & & Los 40 \\
\hline
\end{tabular}




\begin{tabular}{|l|l|c|c|c|c|c|c|c|c|l|l|}
\hline $\begin{array}{l}\text { Radio Región S.A. (Gran } \\
\text { Canaria) }\end{array}$ & --- & 1 & 1 & & & & 1 & & Radio Región \\
\hline $\begin{array}{l}\text { Radiodifusión Fuerteventu- } \\
\text { ra S.A. (Fuerteventura) }\end{array}$ & --- & 1 & 1 & & & & & & 1 & $\begin{array}{l}\text { Onda Fuerte- } \\
\text { ventura* }\end{array}$ \\
\hline $\begin{array}{l}\text { Sonido e Imagen de Cana- } \\
\text { rias (Lanzarote) }\end{array}$ & --- & 1 & 1 & & & & & & 1 & SER \\
\hline $\begin{array}{l}\text { Ideas Milenium S.L. (Te- } \\
\text { nerife) }\end{array}$ & --- & 1 & 1 & & & & 1 & & & & $\begin{array}{l}\text { Radio Mile- } \\
\text { nium Mix }\end{array}$ \\
\hline $\begin{array}{l}\text { Radio Atlántida Santa Úr- } \\
\text { sula S.L. (Tenerife) }\end{array}$ & --- & 1 & 1 & & & & 1 & & & $\begin{array}{l}\text { Radio Atlánti- } \\
\text { da Tenerife }\end{array}$ \\
\hline $\begin{array}{l}\text { Radio Gigante S.L. (Tene- } \\
\text { rife) }\end{array}$ & $\begin{array}{l}\text { Radio y Televisión } \\
\text { Gigante (Tenerife) }\end{array}$ & 1 & 1 & & & & 1 & & & & $\begin{array}{l}\text { Radio Gigan- } \\
\text { te* }\end{array}$ \\
\hline $\begin{array}{l}\text { Gabriel Cerro Moreno (Se- } \\
\text { villa) }\end{array}$ & Unipersonal & 1 & 1 & & & & 1 & & & & Rock FM \\
\hline $\begin{array}{l}\text { Radio 21 Tenerife S.A.L. } \\
\text { (Tenerife) }\end{array}$ & $\begin{array}{l}\text { Prensa Ibérica Me- } \\
\text { dia (Barcelona) }\end{array}$ & 1 & 1 & & & & 1 & & & & No consta \\
\hline $\begin{array}{l}\text { Cadena Hit Radio Canarias } \\
\text { S.A.U. (Tenerife) }\end{array}$ & --- & 1 & 1 & & & & 1 & & & $\begin{array}{l}\text { Onda Tene- } \\
\text { rife }\end{array}$ \\
\hline
\end{tabular}

\section{Anexo III. Canarias: concesionarios de licencia para la emisión de contenidos de TDT local}

*Nota: No se ha podido certificar que esta frecuencia emita a través de su frecuencia asignada. Elaboración propia a partir del Registro Público de Concesiones, de la base de datos SABI y de la información corporativa facilitada por cada medio

\begin{tabular}{|c|c|c|c|c|c|c|}
\hline Sociedad concesionaria & Titularidad & $\begin{array}{l}\text { Número de } \\
\text { licencias }\end{array}$ & Canal $^{12}$ & $\begin{array}{l}\text { Tipo de } \\
\text { licencia }\end{array}$ & Isla & $\begin{array}{l}\text { Canal en emisión } \\
\text { (si opera) }\end{array}$ \\
\hline $\begin{array}{l}\text { Tele Canal } 4 \text { Tenerife S.A.U. } \\
\text { (Tenerife) }\end{array}$ & Privada & 1 & 30 & Local & Tenerife & Canal 4 \\
\hline \multirow{2}{*}{ Publikeira S.L. (Gran Canaria) } & \multirow{2}{*}{ Privada } & \multirow{2}{*}{2} & 40 & Local & Gran Canaria & Canal 4 \\
\hline & & & 44 & Local & Gran Canaria & Canal 4 \\
\hline \multirow{2}{*}{$\begin{array}{l}\text { Diario independiente Canarias } \\
\text { S.L. (Gran Canaria) }\end{array}$} & \multirow{2}{*}{ Privada } & \multirow{2}{*}{2} & 40 & Local & Gran Canaria & TIC Canal 8 \\
\hline & & & 44 & Local & Gran Canaria & UDTV \\
\hline \multirow{2}{*}{$\begin{array}{l}\text { Las Arenas Canal } 9 \text { Canarias } \\
\text { S.L. (Gran Canaria) }\end{array}$} & \multirow{2}{*}{ Privada } & \multirow{2}{*}{2} & 43 & Local & Fuerteventura & Tindaya TV \\
\hline & & & 28 & Local & Lanzarote & Biosfera TV \\
\hline $\begin{array}{l}\text { U.T.E. Gran Canaria Televisión } \\
7 \text { (Gran Canaria) }\end{array}$ & Privada & 1 & 44 & Local & Gran Canaria & Gran Canaria TV \\
\hline \multirow{2}{*}{$\begin{array}{l}\text { U.T.E. Canal } 7 \text { - Gran Canaria } \\
\text { TV (Gran Canaria) }\end{array}$} & \multirow{2}{*}{ Privada } & \multirow{2}{*}{2} & 40 & Local & Gran Canaria & Gran Canaria TV \\
\hline & & & 58 & Local & Gran Canaria & Gran Canaria TV \\
\hline $\begin{array}{l}\text { Consorcio Sur Gran Cana- } \\
\text { ria para la TDT Local Demar } \\
\text { (Gran Canaria) }\end{array}$ & Pública & 1 & 40 & Local & Gran Canaria & Este canal \\
\hline $\begin{array}{l}\text { Ayuntamiento de Mogán (Gran } \\
\text { Canaria) }\end{array}$ & Pública & 1 & 58 & Local & Gran Canaria & Mogán RTV \\
\hline \multirow{3}{*}{$\begin{array}{l}\text { Asociación Ojos Solidarios } \\
\text { ONG (Gran Canaria) }\end{array}$} & \multirow{3}{*}{ Privada } & \multirow{3}{*}{3} & 52 & Local & Gran Canaria & Canal 13 Digital \\
\hline & & & 43 & Local & Fuerteventura & Canal 13 Digital \\
\hline & & & 28 & Local & Fuerteventura & Canal 13 Digital \\
\hline
\end{tabular}

\footnotetext{
12 Con la entrada en vigor del Real Decreto 391/2019, de 21 de junio, por el que se aprueba el Plan Técnico Nacional de la Televisión Digital Terrestre y se regulan determinados aspectos para la liberación del segundo dividendo digital, los concesionaros de los canales radioeléctricos 49 a 69 han de migrar sus emisiones. Dicha migración comenzó en Canarias en el mes de noviembre de 2019 y se encuentra en curso.
} 


\begin{tabular}{|c|c|c|c|c|c|c|}
\hline \multirow{5}{*}{ Telelínea Local S.A. (Madrid) } & \multirow{5}{*}{ Privada } & \multirow{5}{*}{5} & 28 & Local & La Palma & $\begin{array}{l}\text { Telelínea (sin emi- } \\
\text { sión) }\end{array}$ \\
\hline & & & 37 & Local & Fuerteventura & Mírame TV \\
\hline & & & 28 & Local & Tenerife & Sin datos \\
\hline & & & 58 & Local & Gran Canaria & Sin datos \\
\hline & & & 34 & Local & El Hierro & Sin datos \\
\hline $\begin{array}{l}\text { Asociación Cultural Aguacabra } \\
\text { (Fuerteventura) }\end{array}$ & Privada & 1 & 37 & Local & Fuerteventura & Sin datos \\
\hline Federación Incode (Tenerife) & Privada & 1 & 30 & Local & Tenerife & Mirame $T V$ \\
\hline \multirow{3}{*}{$\begin{array}{l}\text { U.T.E. Estudios Ópalo - Torra- } \\
\text { bonaf Sport- } 7 \text { Cantabria Digital } \\
\text { TV (Tenerife) }\end{array}$} & \multirow{3}{*}{ Privada } & \multirow{3}{*}{3} & 37 & Local & Fuerteventura & Sin datos \\
\hline & & & 30 & Local & Tenerife & Gigante $T V^{*}$ \\
\hline & & & 34 & Local & El Hierro & Sin datos \\
\hline $\begin{array}{l}\text { Producciones Radio Televisiva } \\
\text { Taburiente S.L. (Tenerife) }\end{array}$ & Privada & 1 & 28 & Local & La Palma & Canal $11 \mathrm{TV}$ \\
\hline Radio Gigante S.L. (Tenerife) & Privada & 1 & 28 & Local & Tenerife & Gigante $T V^{*}$ \\
\hline $\begin{array}{l}\text { Explotaciones Arainme S.L.U. } \\
\text { (Tenerife) }\end{array}$ & Privada & 1 & 38 & Local & Tenerife & Mírame TV \\
\hline \multirow{2}{*}{$\begin{array}{l}\text { Canal } 8 \text { Medios Audiovisuales } \\
\text { S.L. (Tenerife) }\end{array}$} & Privada & 1 & 33 & Local & La Palma & $\begin{array}{l}\text { Canal } 8 \text { (sin emi- } \\
\text { sión) }\end{array}$ \\
\hline & Privada & 1 & 47 & Insular & Tenerife & Contigo TV \\
\hline $\begin{array}{l}\text { Grupo de Medios de Tenerife } \\
\text { (Tenerife) }\end{array}$ & Privada & 1 & 47 & Insular & Tenerife & El Día TV \\
\hline $\begin{array}{l}\text { Cabildo Insular de Tenerife } \\
\text { (Tenerife) }\end{array}$ & Pública & 1 & 47 & Insular & Tenerife & Tenerife 2030 \\
\hline
\end{tabular}

Azahara Cañedo es Profesora Ayudante Doctora de la Facultad de Comunicación de la Universidad de Castilla-La Mancha donde integra el grupo de investigación Comunicación Pública: Poder, Derecho y Mensaje (COMPUBLIC). Licenciada en Comunicación Audiovisual y Doctora en Investigación en Medios de Comunicación por la Universidad Carlos III de Madrid con mención internacional, su tesis doctoral ha sido galardonada con el Primer Premio ATIC 2020 a la Mejor Tesis Doctoral en Información y Comunicación. Desde la perspectiva investigadora crítica de la Economía Política de la Comunicación, sus principales líneas de investigación se centran en el análisis de las industrias culturales, las políticas de comunicación y la comunicación de proximidad. ORCID: https://orcid.org/0000-0003-2308-5900. 